$x^{2}$

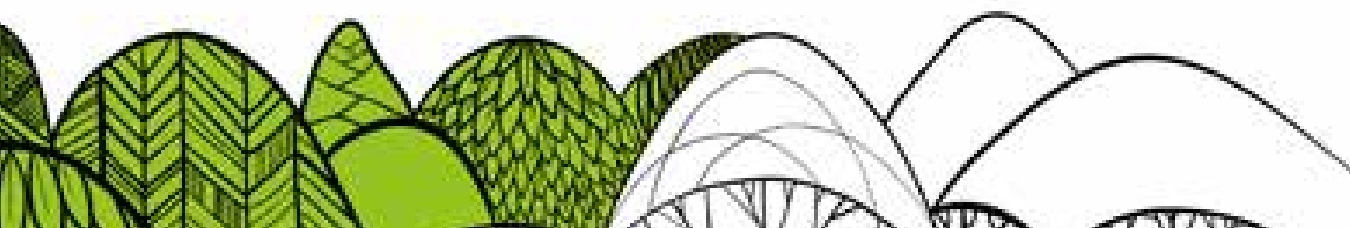
mal I $x=1$ .
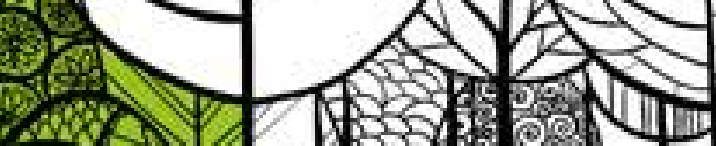
6. 11

a $x=1 \mathrm{x}$

an 5 - 53

(1) $=0$

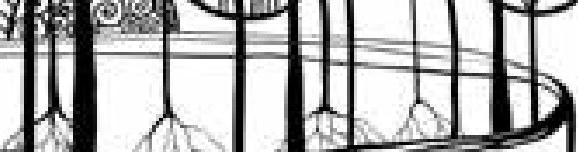

(1)

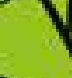

.
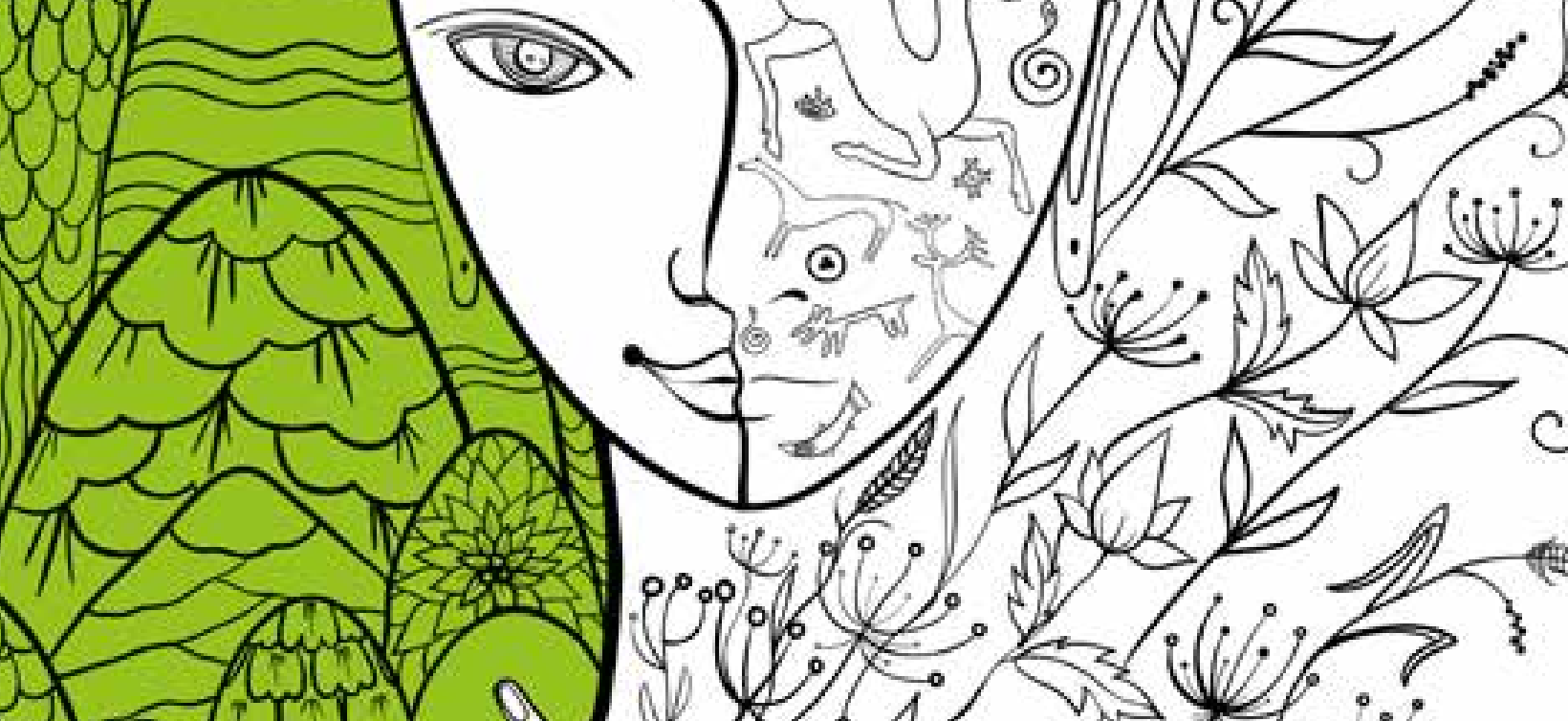
()

4

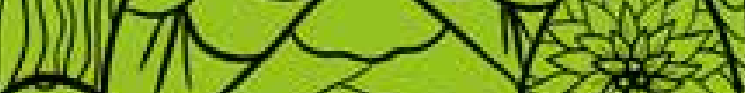

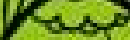

(T)

.
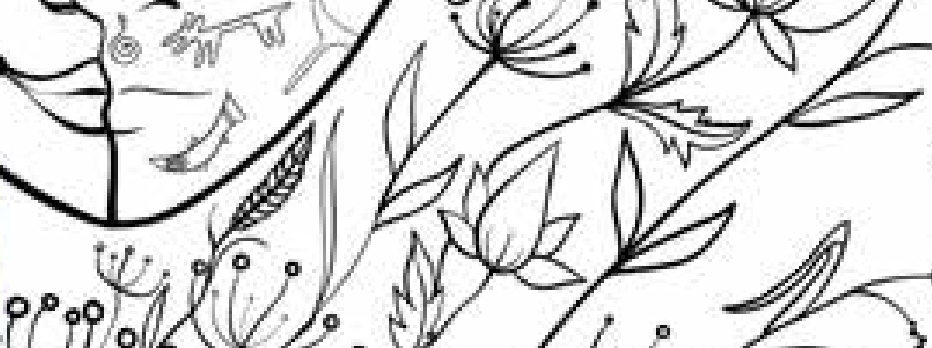

9090162

a)

(2)
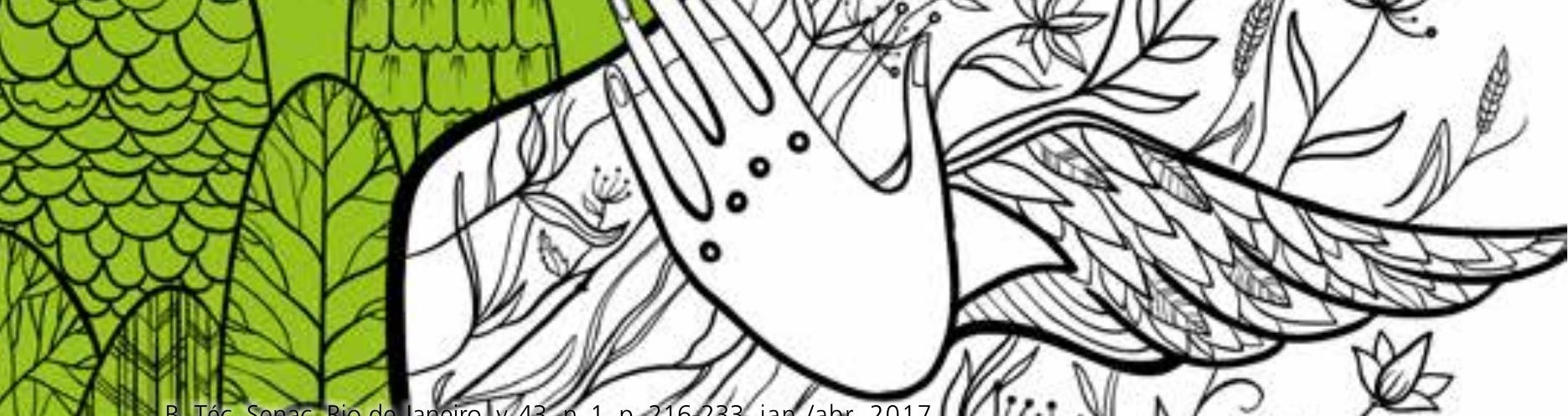

18 NG

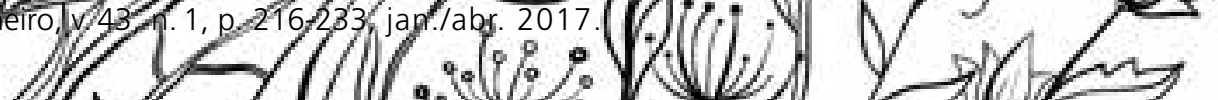




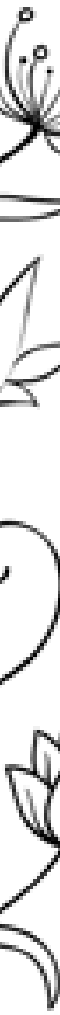

\section{PROGRAMA MAIS EDUCAÇÃO COMO ESTRATÉGIA PARA A ESCOLARIZAÇÃO DE TEMPO INTEGRAL: UM ESTUDO DE CASO SOBRE O MACROCAMPO EDUCAÇÃO AMBIENTAL}

MORE EDUCATION (MAIS EDUCAÇÃO) PROGRAM AS
A STRATEGY FOR FULL TIME SCHOOL HOURS: A CASE
STUDY ON THE MACRO FIELD OF ENVIRONMENTAL
EDUCATION EL PROGRAMA MÁS EDUCACIÓN COMO ESTRATEGIA
PARA LA ESCOLARIZACIÓN A TIEMPO COMPLETO:
UN ESTUDIO DE CASO SOBRE EL MACROCAMPO
EDUCACIÓN AMBIENTAL

Dayana Nascimento Carvalho* Geovana Ferreira Melo**

* Graduada em Ciências Biológicas pela Universidade Federal de Uberlândia (UFU) Estudante de Pós-graduação na Faculdade de Educação (FACED) - UFU. Uberlândia, Minas Gerais, Brasil. E-mail: dayana.n.carvalho@gmail. com

** Doutora em Educação pela Universidade Federal de Goiás (UFG). Professora Associada na FACED - UFU. Uberlândia, Minas Gerais, Brasil. E-mail: geovana. melo@gmail.com

Recebido para publicação em: 18.5.2016

Aprovado em: 2.3.2017

\section{Resumo}

Como o Programa Mais Educação se desenvolve e qual sua importância na escola dentro do macrocampo da Educação Ambiental é o foco deste estudo de caso, orientado pelo questionamento: quais as contribuições do Programa Mais Educação para a escolarização em tempo integral? Identificou-se que suas ações formativas construíram com os estudantes a concepção de que estão intimamente ligados ao meio ambiente e são agentes transformadores capazes de modificar seu redor e multiplicar suas ações. O propósito do programa foi alcançado para a maioria dos envolvidos, conforme avaliações processuais realizadas.

Palavras-chave: Programa Mais Educação. Educação integral. Política pública. Educação ambiental.

\section{Abstract}

The development of the More Education Program and its importance in school within the macro field of environmental education is the focus of this case study, guided by the question: What are the contributions of the More Education Program to 
full time school hours? The conclusion was that the training actions offered to students resulted in the idea that they are closely connected to the environment and are transforming agents able to modify their surroundings and multiply their actions. The purpose of the Program was achieved for most of those involved, pursuant to the procedural assessments performed.

Keywords: More Education Program. Full-time Education. Public Policy. Environmental Education.

\section{Resumen}

De qué manera se desarrolla el Programa Más Educación y cuál es su importancia en la escuela dentro del macrocampo de la Educación Ambiental es el foco de este estudio de caso, guiado por la siguiente interrogante: ¿Cuáles son las contribuciones del Programa Más Educación a la escolarización de tiempo completo? Se identificó que sus acciones educativas cimentaron en los estudiantes la concepción de que están íntimamente conectados al medioambiente y de que son agentes transformadores capaces de modificar sus circunstancias y potenciar su praxis. El propósito del Programa se cumplió para la mayoría de los involucrados, según revelan las evaluaciones procesuales realizadas.

Palabras clave: Programa Más Educación. Educación integral. Política pública. Educación ambiental.

\section{Introdução}

A educação básica, no Brasil, especialmente pós Lei de Diretrizes e Bases da Educação Nacional (LDB) - Lei n. 9.394/96 - enfrenta graves problemas, dos quais se destacam: retenção e evasão, despreparo dos professores, expansão do ensino médio, analfabetismo, insuficiência nos processos de inclusão, entre outros. O enfrentamento desses desafios requer a criação de políticas públicas que têm como objetivo o fortalecimento dos processos educacionais, além de minimizar a distância que há entre a educação brasileira e os padrões internacionais. Entre as ações criadas, o Programa Mais Educação prevê medidas de ampliação da jornada escolar em todo território nacional (CRISPIM, 2014).

A partir das metas do Plano de Desenvolvimento da Educação (PDE), que consiste em um plano executivo composto por diferentes programas para melhorar a qualidade da educação pública, foi criado como parte integrante o Programa Mais Educação. Esse Programa, instituído pela Portaria Interministerial n. 17/2007 e regulamentado pelo Decreto n. 7.083/10, constitui-se 
como estratégia do Ministério da Educação (MEC) para induzir a ampliação da jornada escolar e a organização curricular na perspectiva da Educação Integral. Nesse sentido, houve o incentivo para que as escolas públicas estaduais, municipais e do Distrito Federal pudessem fazer a adesão ao programa, o que ocasionou aumento no número de escolas que oferecem educação em tempo integral no Brasil (MOLL, 2012).

A educação integral está presente na legislação educacional brasileira e faz parte de ações previstas no PDE, que prevê a formação dos estudantes além da escola, com a participação da família e da comunidade. A implementação dessas ações educacionais nas escolas exige superação de grande parte de modelos educacionais, pautados em metodologias e práticas tradicionais, ainda centradas no professor. É preciso romper com velhas práticas que não mais produzem efeitos formativos e buscar novas perspectivas teórico-metodológicas, que perpassem diferentes conteúdos, desde a sustentabilidade ambiental a direitos humanos, buscando valorizar as diferenças das relações entre a escola e sociedade. Ao mesmo tempo, a busca pela adequação do projeto pedagógico, a formação e preparação de professores e demais corpo estrutural da escola constituem-se mudanças precípuas, assim como a necessidade de criar condições materiais efetivas, inclusive de infraestrutura.

O Programa Mais Educação é operacionalizado pela Secretaria de Educação Básica (SEB), por meio do Programa Dinheiro Direto na Escola (PDDE) do Fundo Nacional de Desenvolvimento da Educação (FNDE). Esse programa prevê a consolidação de processos de educação integral, com a ampliação do tempo mínimo de sete horas diárias na jornada dos estudantes, especificadamente para as escolas de redes estaduais e municipais, delimitando, inicialmente, as escolas que apresentam baixo Índice de Desenvolvimento da Educação Básica (Ideb) situadas em capitais e regiões metropolitanas.

O Mais Educação representa a política de educação em tempo integral nacional mais recente (ROSA, 2012), que prevê a oferta de atividades socioeducativas no contraturno escolar dos estudantes. Dessa forma, sua estrutura metodológica está respaldada de forma abrangente pelos macrocampos: Acompanhamento Pedagógico, Educação Ambiental, Esporte e Lazer, Direitos Humanos e Cidadania, Cultura e Artes, Inclusão Digital, Comunicação e Uso das Mídias, Promoção da Saúde, Alimentação e Prevenção, Investigação no campo das Ciências da Natureza e Educação Econômica.

Para o desenvolvimento das atividades, o programa propõe que não se utilize de professores da própria escola, mas que preferencialmente o trabalho seja realizado por estudantes universitários que tenham formação específica nas áreas de atuação das atividades, ou pessoa da comunidade que possua as habilidades apropriadas. E na organização dessas atividades há um coordenador, professor comunitário, representante da escola ou membro da 
comunidade com estreito vínculo com a escola, responsável por coordenar as atividades semanalmente e integrar a comunidade com a escola.

Nesse sentido, o programa proporciona novas oportunidades educativas aos estudantes e com maior integração e participação da comunidade. Assim, o processo de escolarização envolvido está conectado aos interesses do universo dos estudantes, repercutindo em uma maior aceitação e expansão dessa educação integral nas escolas. Essa estratégia permite o fortalecimento dos princípios de organização curricular ligados à contextualização e à interdisciplinaridade, uma vez que os temas desenvolvidos estão diretamente relacionados aos interesses dos estudantes, sendo tratados de forma articulada aos demais conteúdos escolares.

Cada macrocampo do programa possui sua intencionalidade pedagógica, contudo, este estudo de caso focaliza a Educação Ambiental. Esta ênfase justifica-se por sua função social, pois, ao trabalhar a referida temática de forma efetiva e atrativa com os estudantes, torna-se possível construir e vivenciar valores sociais que podem ser replicados na comunidade, iniciando pelos parentes mais próximos. Além disso, há oportunidade de desencadear transformações e conscientização ambiental acerca das práticas sustentáveis em uma maior escala, que melhora a vida das pessoas e beneficia o meio ambiente.

A Educação Ambiental (EA) envolve a construção de uma atitude ecológica respaldada em conduta moral, valores e ética, conduzida pelos ideais de vida de um sujeito ecológico (CARVALHO, 2008). Dessa forma, o papel e a importância da EA para crianças, como proposta permanente dentro das escolas e no âmbito social, contribuem para o aprofundamento da dimensão humanista na formação das pessoas, que ao passar do tempo, serão capazes de multiplicar condutas e valores de um sujeito ecológico. Ainda na perspectiva de Carvalho (2008, p. 67):

O sujeito ecológico agrega uma série de traços, valores e crenças e poderia ser descrito em facetas variadas. Em sua versão política, poderia ser apresentado como sujeito heróico, vanguarda de um movimento histórico, [...] protagonista de novo paradigma político-existencial. Em sua versão Nova Era, é visto como alternativo, integral, equilibrado, harmônico, planetário, holista. Em sua versão gestor social, supõe-se que partilhe de uma compreensão política e técnica da crise socioambiental, sendo responsável por adotar procedimentos e instrumentos legais para enfrentá-la, por mediar os conflitos e planejar ações.

O objetivo do texto é apresentar a análise do programa a partir de seu desenvolvimento na escola, em específico do macrocampo da Educação Ambiental, conforme previsto em suas subáreas do Manual Operacional de 
Educação Integral de 2014. Além disso, propõe-se a refletir sobre as experiências pedagógicas significativas produzidas diretamente na escola.

\section{Metodologia}

A abordagem da investigação é qualitativa, sendo este enfoque relevante por possibilitar a diversificação de perspectivas para compreender o objeto de estudo. De acordo com Bogdan e Biklen (1994, p. 49), na pesquisa qualitativa "tudo tem potencial para constituir uma pista que nos permita estabelecer uma compreensão mais esclarecedora do nosso objeto de estudo". Trata-se de construir abstrações à medida que os dados vão sendo construídos e categorizados. Nessa abordagem, o investigador não recolhe dados com o objetivo de confirmar hipóteses construídas previamente, mas, os elabora, os categoriza e constrói suas interpretações. Dessa forma, as análises são carregadas de sentido e de intencionalidades pelo pesquisador e não há, portanto, como ser neutro ou mesmo imparcial, o que requer do pesquisador uma maior acuidade no sentido de compreender o objeto de pesquisa sem se deixar contaminar por pré-julgamentos ou evidências aparentes (MELO, 2007).

Também se optou pelo estudo de caso, por possibilitar a observação detalhada de um contexto ou de um acontecimento específico. Nesse tipo de pesquisa, o objeto poderá ser apreendido de forma mais aprofundada, principalmente porque o contexto em que ele se situa é considerado no processo de construção das interpretações. As múltiplas dimensões em que o objeto se situa estão, dessa forma, presentes na totalidade e devem ser consideradas na análise.

A opção pelo estudo de caso torna-se relevante quando se pretende aprofundar a compreensão de uma situação particular, considerando seu contexto, sua complexidade, suas minúcias e múltiplas variáveis. O estudo de caso possibilita o aprofundamento amplo e integrado do objeto, portanto, requer do pesquisador a busca incessante de pistas por meio de um trabalho de campo intensificado. Mazzotti (2006, p. 650) esclarece que "o estudo de caso qualitativo constitui uma investigação de uma unidade específica, situada em seu contexto, selecionada segundo critérios predeterminados e, utilizando múltiplas fontes de dados". Sendo assim, faz-se relevante a adoção de critérios claros e explícitos que justifiquem o estudo como realmente "um caso" que mereça ser estudado de forma aprofundada.

Nessa investigação justifica-se a escolha pelas atividades desenvolvidas no Programa Mais Educação, por meio do macrocampo de Educação Ambiental, devido aos seus objetivos no sentido de proporcionar a construção de valores sociais, conhecimentos, habilidades e atitudes voltadas para a susten- 
tabilidade socioambiental e econômica. Além disso, na presente pesquisa, considera-se como princípio e eixo articulador o foco na construção da cidadania de crianças de uma escola municipal situada em um bairro periférico da cidade de Uberlândia - MG, situada na região do Triângulo Mineiro.

Diante do exposto, este estudo de caso representa uma particularidade, ou seja, o estudo de um contexto específico - o contexto de uma Escola da Rede Municipal de Educação, na cidade de Uberlândia - MG, que oferece turmas para os anos iniciais do ensino fundamental, do $1^{\mathrm{O}}$ ao $5^{\mathrm{o}}$ ano. As atividades do Programa Mais Educação foram desenvolvidas com quatro turmas com idades entre 6 e 11 anos, duas no período da manhã e duas no período da tarde. Estas turmas eram divididas por anos e em alguns casos alocadas por grau intelectual, assim, no período da manhã, uma turma composta por $2^{\mathrm{O}}$ e $3^{\mathrm{O}}$ anos e outra por $4^{\mathrm{O}}$ e $5^{\mathrm{O}}$ anos; e no período da tarde, uma turma composta por $1^{\circ}, 2^{\circ}$ e $3^{\circ}$ anos e outra por $4^{\circ}$ e $5^{\circ}$ anos. A opção por esse cenário de pesquisa justificou-se em função de sua localização - um bairro periférico da cidade, conforme enunciado anteriormente, portanto, marcado por maior vulnerabilidade social. Além desse critério, destaca-se o envolvimento dos sujeitos (professores, pais, estudantes, monitores) nas diferentes etapas de desenvolvimento do referido programa, especificamente, no macrocampo da Educação Ambiental, tornando esse cenário significativo para a compreensão do PME.

O estudo de caso deve ser usado quando se está interessado em uma instituição, uma pessoa, ou um programa específico; quando se quer conhecer essa instância particular em sua complexidade e totalidade; quando se estiver interessado mais no processo que nos resultados; especialmente quando se deseja registrar a dinâmica de uma situação da forma mais próxima de seu acontecimento natural (ANDRÉ, 1995). Grande parte dos dados foi obtida por meio da técnica de observação, por possibilitar a percepção do que foi dito e o que não foi dito. Na observação:

O que temos diante de nós é a necessidade de tradução de comportamentos observados, de ritos socialmente reconhecidos, de crenças compartilhadas e, por isso, é preciso encontrar formas de descrição que possam tornar estes elementos mais compreensíveis, mais nitidamente inseridos numa rede de significados que lhes dão sentidos e materializam sua existência (TURA, 2003, p. 190).

O pesquisador precisa fazer-se sujeito, vigilante e rigoroso com suas opções e ações, comprometido politicamente com o conhecimento que produz. Suas concepções de conhecimento, de educação, de formação devem estar afinadas com as abordagens de investigação que assumirá, e também devem ser explicitadas metodologicamente durante todo o processo de pesquisa. Neste caso, houve a necessidade de rigorosa atenção no decorrer das atividades desenvolvidas, no sentido de apreender o objeto em sua totalidade.

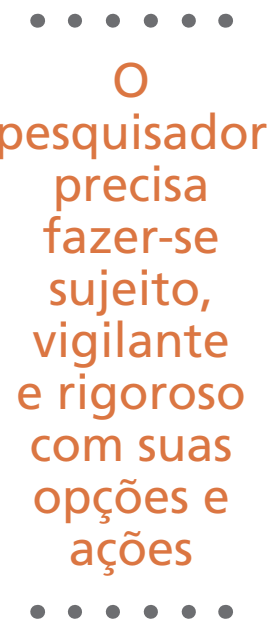


Entre as atividades desenvolvidas no programa, destacam-se as oficinas que foram organizadas com carga horária de 12 horas semanais, com duração de cinco meses, de março a julho de 2015. Destacam-se a perspectiva do trabalho interdisciplinar em que EA articulava-se a outras áreas, a saber: Artesanato, Apoio Pedagógico, Música e Dança. A Oficina de Meio Ambiente, assim denominada pela escola, durante a semana e nos dias estabelecidos, era dividida com mais uma das oficinas por período. A oficina de meio ambiente, principalmente, era realizada na área externa da escola, não somente pela oportunidade de trabalhar e relacionar os diversos temas previstos no programa, mas, por serem atividades no contraturno dos estudantes e o espaço físico já era mais delimitado pela ocupação das salas de aula. A temática trabalhada foi baseada no Manual Operacional de Educação Integral de 2014 do programa, dividida em etapas.

Nas primeiras semanas do mês de março foram trabalhadas atividades práticas que propunham combater o desperdício e a degradação, ao mesmo tempo que refletiam sobre a importância da manutenção da biodiversidade para a melhoria do meio ambiente e da qualidade de vida. Nos meses de abril e maio, foi realizada a implantação de uma horta, composta por temperos como espaço educador sustentável, uma composteira e, posteriormente, outro espaço para cultivo de plantas medicinais. No mês de junho e julho, houve a construção de um jardim escolar constituído de plantas ornamentais como espaço de cuidados e de interação com a biodiversidade. Paralelamente a essas práticas sustentáveis, foram trabalhados conteúdos pertinentes às áreas científicas que embasaram essas ações.

\section{Discussão: Programa Mais Educação na escola e suas contribuições}

O PME, ao prever e assegurar a ampliação do tempo de permanência na escola, constitui-se como estratégia importante para a constituição de uma cultura que valoriza a escola pública de tempo integral, sobretudo, por sua proposta inovadora. Dessa forma, considera-se que o referido programa dá um salto qualitativo na configuração e nos modos de organizar tempos e espaços escolares. De acordo com Moll (2012, p. 133):

A identidade do Programa Mais Educação é a sua preocupação em ampliar a jornada escolar modificando a rotina da escola [...]. Esse aspecto refere-se ao esforço para contribuir no redimensionamento da organização seriada e rígida dos tempos na vida da escola, contribuição esta reconhecida nos conceitos de ciclos de formação que redimensionam os tempos de aprendizagem e de cidade educadora, território educativo, comunidade de aprendizagem que pautam novas articulações entre os saberes escolares, seus agentes (professores 
e estudantes) e suas possíveis fontes. Esses últimos articulam as relações entre cidade, comunidade, escola e os diferentes agentes educativos, de modo que a própria cidade se constituía como espaço de formação humana.

Um programa dessa natureza, que proporciona investimentos físico-financeiros nas escolas, especialmente aquelas com baixos índices de desenvolvimento da educação, tem o potencial para se constituir em políticas afirmativas capazes de contribuir para a diminuição da retenção e evasão escolar, problemas históricos na educação brasileira.

Assim, as diferentes concepções de acesso, acolhimento e vínculo no processo de construção do ensino podem proporcionar o estabelecimento de estratégias com vistas a aprimorar a Escola de Tempo Integral e assegurar a formação integral. Desse modo, é de extrema importância fortalecer o diálogo e a ação entre diferentes setores da sociedade, para que seja possível ampliar a consciência acerca da vulnerabilidade (CORÁ; TRINDADE, 2015, p. 91-92).

De acordo com Corá e Trindade (2015) o Programa Mais Educação aflora como estratégia que contribui para associar o meio escolar e os profissionais da educação, para uma atuação em conjunto no ambiente escolar, especialmente, nas ações voltadas para a promoção da educação das crianças e adolescentes, em uma perspectiva de ampliação do tempo de permanência na escola, pautada por atividades planejadas e desenvolvidas de modo significativo.

Arroyo (2012, p. 33), ao argumentar sobre a relevância da educação integral, defende-a como ascendência da "consciência política de que ao Estado e aos governantes cabe o dever de garantir mais tempo de formação, de articular os tempos-espaços de seu viver, de socialização". No entanto, Arroyo alerta sobre os riscos de uma educação integral limitada a oferecer a ampliação do tempo escolar, ou mais um turno, pautado na duplicidade de atividades, ou seja: "[...] mais educação do mesmo tipo de educação" (ARROYO, 2012, p. 33), o que, segundo o referido autor, seria "uma forma de perder seu significado político".

Uma educação integral capaz de contribuir para a melhoria da qualidade socialmente referenciada da educação escolar, deverá, portanto:

Desenvolver os educandos na especificidade de seus tempos-ciclos, da infância, da adolescência, da juventude ou da vida adulta. [...] As idades da vida da formação humana passam a ser o eixo estruturante do pensar, planejar, intervir e fazer educativos, da organização das atividades, dos conhecimentos, dos valores, dos tempos e espaços. Trabalhar em um determinado tempo-ciclo da formação humana passa a ser o eixo identitário dos profissionais da educação básica e de seu trabalho coletivo e individual (ARROYO, 1999, p. 158). 
Nessa perspectiva apontada por Arroyo (1999), o macrocampo da Educação

macrocampo da Educação Ambiental propõe a construção de valores sociais
Ambiental propõe a construção de valores sociais, conhecimentos, habilidades, competências e atitudes voltadas para a sustentabilidade socioambiental e econômica. Ao mesmo tempo, a compreensão da função social dos tributos, controle social e uma educação voltada para a cidadania, para o consumo consciente e responsável (BRASIL, 2014).

A escolha pelos macrocampos é feita pela própria escola, limitando-se entre três a quatro, sendo que o macrocampo Acompanhamento Pedagógico é obrigatório. A partir disso, optar por cinco ou seis atividades para serem desenvolvidas com os estudantes. A escola de estudo era dividida em três macrocampos: Acompanhamento Pedagógico; Cultura, Artes e Educação Patrimonial; e Educação Ambiental e Desenvolvimento Sustentável. As atividades eram divididas em cinco oficinas, denominadas Apoio Pedagógico, Artesanato, Meio Ambiente, Dança e Música. Em estudos feitos em uma escola de Rede Estadual do Estado do Pará, o Programa Mais Educação atende outros macrocampos, a saber: Acompanhamento Pedagógico (Letramento e Matemática) e Cultura, Artes e Educação Patrimonial (Dança, Teatro, Banda de Fanfarra) para um total de 400 estudantes (SANTOS; PAES NETO, 2012).

Na escola campo do estudo, o programa foi estruturado por monitores entre os quais se incluíam estudantes universitários e professores da comunidade que ministram aulas em associação de bairros ou outros programas sociais. As oficinas de Artesanato, Apoio Pedagógico, Música e Dança foram organizadas por monitores da comunidade com experiências na área temática e apenas a monitora de Meio Ambiente era estudante universitária do curso de Ciências Biológicas, área afim para desenvolvimento da oficina. Foi critério para a seleção dos monitores pela escola a experiência no desenvolvimento de atividades de aprendizagem, culturais e artísticas, esportivas e de lazer, de direitos humanos, de meio ambiente, de inclusão digital e de saúde e sexualidade, todas voltadas à educação integral, sendo que tais critérios são determinados conforme as necessidades de cada escola e seus macrocampos (SANTOS; PAES NETO, 2012). Em estudos realizados em uma escola pública de ensino fundamental de Florianópolis - SC, os monitores contratados para atuar no programa, em geral, possuem formação acadêmica e são selecionados por meio de currículo e projeto de trabalho dentro da área para a qual se candidatam (MACHADO; THIESEN, 2014). Essa integração, de fato, está de acordo com a proposta do programa, inclusive, por incluir a participação da comunidade.

A monitoria de Apoio Pedagógico que fazia parte da comunidade foi liberada para fazer cursos de aperfeiçoamento ministrados pelo Serviço Brasileiro de Apoio às Micro e Pequenas Empresas (Sebrae), sobre empreendedorismo, para ser aplicado no programa, a pedido da professora comunitária. Outros estudos, como os realizados na Rede Municipal de Ensino de Natal - 
$\mathrm{RN}$, mostram que os monitores foram capacitados em suas respectivas áreas, pois entendem que os professores são elemento central para uma melhor qualidade da educação (FARIA, 2011). O papel essencial dos professores comunitários para o andamento do programa é evidenciado por meio dos estudos realizados na Rede Municipal de Ensino de Natal, no sentido de destacar que os professores comunitários participavam de reuniões reflexivas, a cada 15 dias, diretamente com técnicos da Secretaria Municipal de Educação (FARIA, 2011).

Em contrapartida, no que se refere aos documentos que constituem o Programa Mais Educação, há críticas que apontam para a ausência de formação prévia ou continuada dos monitores que os ajudariam a compreender meIhor o trabalho nas escolas de tempo integral (AMARAL; VICTOR; ALMEIDA, 2012). Tal realidade demonstra o desinteresse na qualificação e seleção de monitores, o que é um paradoxo, pois essa formação deveria estar diretamente vinculada aos interesses das escolas.

A responsável pelo programa deste estudo de caso é supervisora da escola, formada em Ciências Biológicas, com dedicação de 40 horas semanais para o programa. Com o cargo de professora comunitária, conforme o programa exige, foi responsável por coordenar todas as etapas das atividades, inclusive, a de participar das reuniões periódicas, uma vez ao mês, centralizadas em sua maioria no Centro Municipal de Estudos e Projetos Educacionais (Cemepe), e repassar as decisões aos monitores e interessados da escola.

Entre as atividades havia o planejamento mensal feito por cada monitor e discutido com a professora comunitária, além do acompanhamento diário na prática de tudo que iria ser desenvolvido. No fim de cada mês, esse planejamento e um relatório eram enviados à Secretaria Municipal de Educação, para prestação de contas, como forma de comprovar que o projeto está em andamento, em resultado da verba investida na escola para execução do programa. A importância desses planejamentos contribui como forma de orientação para alcançar um objetivo, para a organização e concretização dos objetivos pretendidos (CARVALHO et al., 2011), ainda mais para estudantes da educação básica, que necessitam de estruturação e apoio pedagógico mais consolidado pela etapa de formação em que se encontram, de construção de valores sociais e intelectuais.

Para a formação dessas turmas, o programa prevê critérios preferenciais para a ampliação da jornada escolar na perspectiva da Educação Integral, a saber: estudantes que apresentam defasagem idade/ano das séries finais da $1 \underline{a}$ fase do ensino fundamental (4으o e/ou 5ำ anos), em que existe maior saída espontânea de estudantes na transição para a $2^{\underline{a}}$ fase e estudantes de anos/séries em que são detectados índices de evasão e/ou repetência. As turmas eram bem diversificadas quanto ao interesse e grau intelectual. Havia estudantes 
mais interessados e que acompanhavam o ritmo das atividades e dos conteúdos, mas também havia estudantes diagnosticados com alguma defasagem pedagógica, inclusive, acompanhados pelo Atendimento Educacional Especializado (AEE) da escola. Para a participação dos estudantes no programa Mais Educação, há uma seleção a partir das necessidades de atendimento diferenciado e da vulnerabilidade social. Dessa forma, é feito um levantamento de quais estudantes apresentam maior necessidade para desenvolver a aprendizagem (MACHADO; THIESEN, 2014). Nas quatro turmas formadas havia estudantes que se encaixavam em algum desses perfis.

Inicialmente, as turmas foram formadas por 25 estudantes por turma, total de 50 estudantes por período. Pelo Programa, cada turma deveria ser composta por 30 estudantes, exceto para as atividades de Orientação de Estudos e Leitura e Campos do Conhecimento, que compõem a Oficina de Apoio Pedagógico, que deveria ter 15 estudantes. Essa diferença na proporção de estudantes entre as oficinas é adequada, a depender das atividades a serem desenvolvidas e a Oficina de Apoio Pedagógico exige maior dedicação individual, até mesmo pela atuação direta nos déficits de aprendizagem dos estudantes. Para a Oficina de Meio Ambiente, o trabalho em grupo foi bastante explorado, inclusive em projetos maiores, que exigiam participação e controle dos estudantes, como a construção da composteira, horta e jardim, foi essencial a contribuição de outro agente da escola. A quantidade de estudantes por turma na escola de estudo parece ser adequada, uma vez que outros estudos possuem também quatro turmas formadas do programa, compostas por 25 estudantes cada, sendo duas no matutino e duas no vespertino (MACHADO; THIESEN, 2014).

No fim do primeiro semestre de 2015, a quantidade inicial de estudantes das quatro turmas reduziu significativamente, pelo cansaço físico e mental dos estudantes e em virtude do próprio horário, que exigia o deslocamento de ida e volta entre períodos e que dependiam da disponibilidade dos responsáveis para a logística.

Durante os cinco meses de estudo, foram trabalhadas grande parte das temáticas presentes dentro do macrocampo Educação Ambiental. Destacou-se a construção da horta escolar composta pelos principais temperos presentes na culinária e uma composteira, que se constituíram em trabalhos importantes no cotidiano da escola e, não somente para os estudantes do programa. Houve uma expansão do interesse e exploração do espaço como recurso didático para os demais estudantes da escola. O plantio de uma horta escolar torna-se excelente ferramenta para impulsionar uma escola sustentável, beneficiando-se com a oferta de alimentos, o aprender a produzir e o despertar nos estudantes do gosto pelo cultivo, que podem gerar ações as quais ultrapassem a escola, ampliando para suas casas e bairro (TRAJBER; CZAPSKI, 2010). 
O envolvimento das turmas do Mais Educação foi considerado exitoso, pois ocorreu de forma organizada e definida, por meio dos cuidados diários de irrigação, reposição de adubos na horta e cuidados primários com a composteira em parceria com a cantina da escola e professora comunitária. Tais atividades foram atribuídas aos estudantes para que fossem desempenhadas durante os horários das oficinas. Paralelamente, foi trabalhada a parte teórica sobre os conteúdos que envolviam as etapas até o produto, desde solo, coleta seletiva a triagem de lixo, reaproveitamento da água, produção de adubo, propriedades das ervas presentes na horta e a composteira. A participação dos estudantes é essencial, desde a fase de planejamento da atividade, a escolha do local mais adequado pelos fatores abióticos (quantidade de luz solar) e fatores bióticos (seleção das espécies da flora mais apropriadas para a região e a época do ano), assim como a importância de se preparar o solo para as demais condições físicas, para que as plantas nasçam e cresçam saudáveis (TRAJBER; CZAPSKI, 2010).

O trabalho da horta inspirou outros professores da escola, com isso, parte do terreno próximo à horta tornou-se uma área de cultivo de plantas medicinais como resultado de um trabalho que uma das professoras repassou à sua turma em parceria com as atividades do Programa Mais Educação. A construção de um jardim também fez parte das atividades. A frente e as laterais da escola foram transformadas com uso de plantas ornamentais comuns de jardins, que não oferecessem perigos aos estudantes, por isso, a importância de saber as espécies e sua relação com os polinizadores.

Entre as atividades desenvolvidas no projeto, destaca-se sua influência não só no processo de ensino-aprendizagem dos estudantes, mas também nas atividades de apoio pedagógico realizadas pela professora responsável. A dinâmica das ações constituiu-se ponto de partida para o aprimoramento das propostas, no sentido de romper com a perspectiva tradicional de "reforço escolar", para ações inovadoras, como: a construção de um jornal da escola com o intuito de trabalhar a parte escrita e leitura dos estudantes, partindo de atividades interativas desde entrevistas com a monitora de Meio Ambiente e fotos do ambiente escolar. Tais experiências despertaram o interesse, a participação e o maior empenho dos estudantes, por se tratar de uma metodologia ativa, que tem o estudante como protagonista do processo. O estudante deve ser o protagonista na educação infantil, não no sentido de fazer tudo o que quer, mas, observar também quais são os interesses desses estudantes para que se possa atendê-los (CARNEIRO, 2010). Outra dimensão trabalhada se refere à temática de empreendedorismo social, vinculado, principalmente, à atividade desenvolvida com a produção dos temperos, resultante da Oficina de Meio Ambiente. 
O uso eficiente da água também foi uma temática importante, ao ser trabalhada no sentido de evitar o desperdício da água de aparelhos de ar-condicionado do laboratório da escola. Dessa forma, foi construído um sistema fechado para reserva da água liberada em um recipiente para posterior uso na irrigação da horta ou jardim. O plantio de hortas e jardins também tiveram importância para além dos aromas, cores e sabores, com a captura de carbono em excesso no ar, que contribui de forma positiva e sustentável no clima do planeta (TRAJBER; CZAPSKI, 2010).

O ensino de ciências na sua mais abrangente relação com a natureza e as práticas sustentáveis também foram trabalhadas, em uma perspectiva interdisciplinar, como potência para instigar a criatividade, proporcionando experiências e conscientização ambiental nos estudantes. Exemplo disso foi a construção de duas maquetes, uma por período, que tiveram como finalidade tornar mais concretas as modificações ocorridas na escola. Essa atividade possibilitou a articulação de diferentes saberes que envolveram as áreas de Artes, Ciência, Geografia, História e Língua Portuguesa, constituindo-se em importante ferramenta pedagógica. Para os estudantes, o ensino de Ciências pode ajudar no desenvolvimento de uma lógica acerca dos fatos do cotidiano, em um crescimento intelectual, além de interferir positivamente em outras áreas, como a Língua Portuguesa e Matemática (BIZZO, 2009).

As atividades desenvolvidas no âmbito do programa foram planejadas tendo como princípio de organização curricular a interdisciplinaridade, sendo evidenciada a integração de conhecimentos e conteúdos escolares próprios de cada série/período com as atividades realizadas pelos monitores do PME. Essa perspectiva metodológica pautada na integração e interação curricular reflete a intencionalidade dos profissionais envolvidos no programa, a de romper com a histórica fragmentação dos currículos.

Todas as atividades manuais resultantes da Oficina de Meio Ambiente, artesanato e as apresentações de grupo das outras oficinas foram expostas e abertas à comunidade, como forma de demonstrar os trabalhos e resultados dos estudantes durante sua participação no Programa Mais Educação. De fato, esta ação confirmou o estreitamento que há entre a escola e a comunidade, conforme foi previsto. 


\section{Considerações finais}

A instituição de um programa como o Mais Educação busca um potencial na melhoria da qualidade da educação pública. Ao mesmo tempo, a oferta de educação integral pela expansão da carga horária visa atender a uma necessidade inicial da escola, de ampliar suas ações educativas. Essa educação integral, em grande parte, tende a aprofundar o desenvolvimento de estudantes, crianças e jovens nas relações sociais entre diferentes gerações, o enriquecimento cultural e uma maior preparação frente à intensa exigência de acesso ao conhecimento. Essa finalidade orientou a organização do programa em nove macrocampos do conhecimento para serem explorados nas escolas e em espaços não formais de educação. Os espaços não formais ou núcleos de divulgação científica, dentro de suas mais variadas formas e termos, sintetizam um local aberto à popularização da ciência por meio de mostras, exposições, atividades, cursos e muitos outros atrativos para o público visitante se aproximar do conhecimento produzido pela ciência (JACOBUCCI, 2008).

O trabalho dos monitores no programa é de caráter voluntário e temporário, a depender da participação da escola em sua renovação. Dentro do valor investido na escola feito pelo programa, há uma verba para pagamento de bolsas aos monitores, correspondente a ajuda de custo apenas para alimentação e vale-transporte. Entretanto, dada a importância da atuação dos monitores no exercício de atividades formativas, o valor deveria ser alterado.

O papel que esses educadores desempenham é fundamental para a qualidade do processo educativo, uma vez que a criação desse programa visa como produto final à qualidade da educação pública. Desta forma, algumas adaptações quanto ao tipo de vínculo dos monitores com as escolas poderiam fortalecer e despertar mais interesse dos educadores. A possibilidade de considerar maior critério para a seleção dos monitores seria importante ao relacionar não só a capacidade, mas também a preparação que um estudante universitário tem como educador, principalmente para turmas com maior faixa etária.

As atividades do macrocampo Educação Ambiental repercutiram em sua grande totalidade em aspectos positivos, com a participação e o envolvimento cada vez mais crescente de grande parte dos estudantes. A horta se tornou o produto-chave para destrinchar muitos dos conteúdos presentes no programa e que exploram uma relação com a natureza e as práticas sustentáveis. Ao mesmo tempo, exigiu mobilização de outros setores da escola para manutenção e preservação do espaço.

Para divisão de tarefas durante a construção da horta, o uso de grupos despertou episódios de indisciplina, necessitando da intervenção da professora 
comunitária como apoio e outro agente da escola que também prestava apoio. Esse trabalho coletivo entre professores e demais integrantes da escola pressupôs relações horizontais solidárias em torno de interesses em comum, mesmo frente ao modelo vertical de hierarquização presente nas escolas.

A partir da análise, é possível afirmar que as ações formativas desenvolvidas nas oficinas contribuíram para construir com os estudantes a concepção de que estão intimamente ligados ao meio ambiente, que são agentes transformadores capazes de modificar seu redor e multiplicar suas ações, baseados em suas escolhas. O propósito e as finalidades do programa foram alcançados, pelo menos para a grande maioria dos estudantes envolvidos, conforme avaliações processuais realizadas.

Frente ao exposto, destaca-se a importância de trabalhos e pesquisas futuras que tenham como foco programas desta natureza, sobretudo, por se tratar de uma política de educação em tempo integral nacional e mais recente, com impactos na dinâmica das escolas. Dessa forma, ressaltam-se as contribuições do Programa Mais Educação para a consolidação da educação integral, na promoção de processos educacionais com qualidade socialmente referenciada.

\section{Referências}

AMARAL, Luisa Figueiredo; VICTOR, Alessandra; ALMEIDA, Érika Christina Gomes de. $O$ Programa Mais Educação e as novas configurações do trabalho docente. In: SEMINÁRIO DO TRABALHO: TRABALHO, EDUCAÇÃO E POLÍTICAS SOCIAIS NO SÉC. XXI, 8., 2012, Marília. Anais... Marília: UNESP, 2012. Disponível em: <http://www. estudosdotrabalho.org/texto/gt1/o_programa_mais_educacao.pdf $>$. Acesso em: 7 set. 2015.

ANDRÉ, Marli Eliza Dalmazo Afonso de (Org.). 0 papel da pesquisa na formação e na prática dos professores. Campinas: Papirus, 1995.

ARROYO, Miguel. Ciclos de desenvolvimento humano e formação de educadores. Educação e Sociedade, Campinas, v. 20, n. 68, p. 143-162, dez. 1999.

ARROYO, Miguel. 0 direito a tempos-espaços de um justo e digno viver. In: MOLL, Jaqueline et al. Caminhos da educação integral no Brasil: direito a outros tempos e espaços educativos. Porto Alegre: Penso, 2012. p. 33-45.

BIZZO, Nélio Marcos Vincenzo. Metodologia e prática de ensino de ciências: a aproximação do estudante de magistério das aulas de ciências no $1^{\circ} \mathrm{grau}$. Belém: UFPA, 2009. Disponível em: <http://www.ufpa.br/eduquim/praticadeensino.htm>. Acesso em: 7 set. 2015. 
BOGDAN, Robert; BIKLEN, Sari Knopp. Investigação qualitativa em educação: uma introdução a teoria e aos métodos. Porto: Porto Ed., 1994.

BRASIL. Ministério da Educação. Secretaria de Educação Básica. Manual operacional de educação integral. Brasília, DF, 2014. Disponível em: <http://portal.mec.gov.br/ index.php?option=com_docman\&view=download\&alias=15842-manual-operacionalde-educacao-integral-2014\&category_slug=junho-2014-pdf\&ltemid=30192>. Acesso em: 7 set. 2015.

CARNEIRO, Maria Ângela Barbato. 0 que é ensinado na educação infantil? São Paulo: Todos pela Educação, 2010. Disponível em: <http://www.todospelaeducacao. org.br/educacao-na-midia/indice/10717/0-que-e-ensinado-na-educacao-infantil>. Acesso em: 7 set. 2015.

CARVALHO, Arivan Santos de et al. 0 ato de planejar e a importância do planejamento na organização do profissional de educação física. EFDeportes.com, Buenos Aires, v.16, n. 156, 2011. Disponível em: <http://www.efdeportes. com/efd156/o-ato-deplanejar-na-educacao-fisica.htm>. Acesso em: 7 set. 2015.

CARVALHO, Isabel Cristina de Moura. Educação ambiental: a formação do sujeito ecológico. São Paulo: Cortez, 2008.

CORÁ, É. J.; TRINDADE, L. L. Intersetorialidade e vulnerabilidade no contexto da educação integral. Educação em Revista, Belo Horizonte, v. 31, n. 4, p. 81-94, out./ dez. 2015.

CRISPIM, Rute Irene Cláudio. A educação integral proposta pelo Programa Mais Educação: revisão bibliográfica. In: CONGRESSO INTERNACIONAL DE EDUCAÇÃO E INCLUSÃO (CINTEDI), 1., 2014, Campina Grande. Anais... Campina Grande: Centro Paraibano de Estudos do Imaginário, 2014. Disponível em: <http://editorarealize. com.br/revistas/cintedi/trabalhos/Modalidade_1datahora_10_11_2014_17_10_49_ idinscrito_4799_ed59b2e6c43a453e73ef26aec6726b06.pdf>. Acesso em: 7 set. 2015.

FARIA, Teresa Cristina Leandro de. Reflexões sobre a implantação do Programa Mais Educação na rede municipal de ensino de Natal, RN. Quipus: revista científica das escolas de comunicação e artes e educação, Natal, v. 1, n. 1, 2011. Disponível em: $<$ https://repositorio.unp.br/index.php/quipus/article/download/58/102>. Acesso em: 7 set. 2015.

JACOBUCCI, Daniela Franco Carvalho. Contribuições dos espaços não-formais de educação para a formação da cultura científica. Em Extensão, Uberlândia, v. 7, p. 55-66, 2008. Disponível em: <http://www.seer.ufu.br/index.php/revextensao/article/ view/20390/10860 >. Acesso em: 7 set. 2015.

MACHADO, Lurdes Regina Borges Lima; THIESEN, Juares da Silva. Educação integral na EBIAS: O Programa Mais Educação como transitoriedade e ação indutora. In: CONGRESSO DE EDUCAÇÃO BÁSICA (COEB), 1., 2014, Florianópolis, SC. Anais... Florianópolis: Secretaria de Educação de Florianópolis, 2014. Disponível em: <https:// repositorio.ufsc.br/bitstream/handle/123456789/105662/Lurdes\%20Regina\%20 Borges\%20\%282\%29.pdf? sequence=1\&isAllowed=y>. Acesso em: 7 set. 2015. 
MAZZOTTI, Alda Judith Alves. Usos e abusos dos estudos de casos. Cadernos de

Pesquisas, São Paulo, v. 36, n. 129, p. 637-651, set./dez. 2006. Disponível em: <http://www.scielo.br/pdf/cp/v36n129/a0736129.pdf>. Acesso em: 7 set. 2015.

MELO, Geovana Ferreira. Tornar-se professor: a formação desenvolvida nos cursos de Física, Matemática e Química da Universidade Federal de Uberlândia. 2007. 223 f. Tese (Doutorado) - Faculdade de Educação, Universidade Federal de Goiás, Goiânia, 2007.

MOLL, Jaqueline et al. Caminhos da educação integral no Brasil: direito a outros tempos e espaços educativos. Porto Alegre: Penso, 2012.

ROSA, Viviane Silva da. O Programa Mais Educação como política pública nacional de educação integral. In: SEMINÁRIO DE PESQUISA EM EDUCAÇÃO DA REGIÃO SUL: ANPED SUL, 9., 2012, Rio Grande do Sul. Anais... Caxias do Sul: Universidade de Caxias do Sul, 2012. Disponível em: <http://www.ucs.br/etc/conferencias/index.php/ anpedsul/9anpedsul/paper/viewFile/1095/129>. Acesso em: 7 set. 2015.

SANTOS, Áurea; PAES NETO, Gabriel. A gestão pedagógica do Programa Mais Educação: um olhar a partir da experiência da EEEFM Profa. Teodora Bentes. In: ENCONTRO INTERNACIONAL DA SOCIEDADE BRASILEIRA DE EDUCAÇÃO COMPARADA (SBEC) AVALIAÇÃO DO RENDIMENTO ESCOLAR: DIMENSÕES INTERNACIONAIS, 5., 2012, Belém. Anais... Belém: Instituto de Ciências Jurídicas da UFPA, 2012. Disponivel em: <http://www.sbec.org.br/evt2012/trab08.pdf>. Acesso em: 7 set. 2015.

TRAJBER, Rachel; CZAPSKI, Silvia. Macrocampo de educação ambiental: mais educação. [Brasília, DF]: Secretaria de Eduação Continuada, Alfabetização e Diversidade do Ministério da Educação, 2010. Disponível em: <http://portal.mec.gov.br/index. php?option=com_docman\&view=download\&alias=8213-educacao-ambiental-finalversao-preliminar-pdf\&category_slug=junho-2011-pdf\&ltemid=30192>. Acesso em: 7 set. 2015.

TURA, Maria de Lourdes Rangel. A observação do cotidiano escolar. In: ZAGRO, Nadir; CARVALHO, Marilia Lia Pinto de; VALÉRIA, Rita Amélia Teixeira (Org.). Itinerários da pesquisa: perspectivas qualitativas em sociologia da educação. Rio de Janeiro: DP\&A, 2003. p. 183-206. 